\title{
Expansion of off-site percutaneous coronary intervention centres significantly reduces ambulance driving time to primary PCI in the Netherlands
}

\author{
N. P. G. Hoedemaker · R. J. de Winter · G. J. Kommer · H. Giesbers · R. Adams · S. E. van den Bosch · P. Damman
}

Published online: 20 July 2020

(c) The Author(s) 2020

\begin{abstract}
Introduction In patients with ST-elevation myocardial infarction (STEMI), percutaneous coronary intervention (PCI)-mediated reperfusion is preferred over pharmacoinvasive reperfusion with fibrinolysis if transfer to a PCI centre can be ensured in $\leq 120 \mathrm{~min}$. We evaluated the ambulance driving time to primary PCI centres in the Netherlands and assessed to what extent ambulance driving times were impacted by the expansion of off-site PCI centres.

Methods and results We calculated the driving routes from every Dutch postal code to the nearest PCI centre with (on-site) or without (off-site) surgical backup. We used data from ambulance records to estimate the ambulance driving time on each route. There were 16 on-site and 14 off-site PCI centres. The median (interquartile range) time to on-site PCI centres was $18.8 \mathrm{~min}(12.2-26.3)$ compared with $14.9 \mathrm{~min}$ $(8.9-20.9)$ to any PCI centre $(p<0.001)$. In postal code areas that were impacted by the initiation of off-site PCI, the median driving time decreased from
\end{abstract}

N. P. G. Hoedemaker $(\bowtie)$

Heart Centre, Department of Cardiology, Onze Lieve Vrouwe Gasthuis, Amsterdam, The Netherlands

n.p.g.hoedemaker@olvg.nl

N. P. G. Hoedemaker · R. J. de Winter · R. Adams · S. E. van den Bosch

Heart Centre, Department of Cardiology, Amsterdam

Cardiovascular Sciences, Amsterdam University Medical Center, AMC/University of Amsterdam, Amsterdam, The Netherlands

\section{G. J. Kommer · H. Giesbers}

National Institute for Public Health and the Environment (RIVM), Bilthoven, The Netherlands

\section{P. Damman}

Department of Cardiology, Radboud University Medical Centre, Nijmegen, The Netherlands
$25.4(18.2-33.1)$ to $14.7 \mathrm{~min}(8.9-20.9)(p<0.001)$. Ambulance driving times of $>120$ min were only seen in non-mainland areas.

Conclusion Based on a computational model, timely ambulance transfer to a PCI centre within $120 \mathrm{~min}$ is available to almost all STEMI patients in the Netherlands. Expansion of off-site PCI has significantly reduced the driving time to PCI centres.

Keywords STEMI · Off-site PCI · Time delay

\section{Introduction}

Percutaneous coronary intervention (PCI) is a commonly used treatment strategy for coronary revascularisation in both stable coronary artery disease and acute coronary syndrome (ACS) [1]. In the past 20 years, PCI has become a cornerstone in ACS treatment, particularly in patients with ST-segment elevation myocardial infarction (STEMI) [2]. Timely treatment plays an important role in the prognosis of STEMI patients [3]. In STEMI patients with symptoms for $<12 \mathrm{~h}$, PCI-mediated reperfusion (wire crossing)

\section{What's new?}

- European guidelines recommend transfer to a percutaneous coronary intervention (PCI) centre if primary PCI can be ensured in $\leq 120 \mathrm{~min}$.

- The expansion of off-site PCI centres in the Netherlands has significantly reduced the driving time to PCI centres.

- Timely ambulance transfer to a PCI centre within $120 \mathrm{~min}$ is available to all patients with ST-elevation myocardial infarction living on the Dutch mainland. 
is preferred over pharmacoinvasive reperfusion with fibrinolysis if transfer to a PCI centre can be ensured in $\leq 120$ min [4]. In addition, the recommended time from STEMI diagnosis to wire crossing during PCI is $\leq 90 \mathrm{~min}$ [4]. Several measures have been taken to reduce time delays, including field triage, transmission of prehospital electrocardiography (ECG), collaboration of healthcare providers in a STEMI-network, and feedback reporting on time intervals [3, 5-7].

In its early days, PCI was only performed in hospitals with on-site back-up for emergency cardiac surgery [8]. However, during the last 10-15 years, the procedure has been expanded to include hospitals without on-site cardiac surgery (off-site PCI). Expansion of off-site PCI centres ensures timely revascularisation in STEMI patients living in remote areas, which was observed in the United States and the United Kingdom (UK) [9-12]. In the Netherlands, the first off-site primary PCI centre was established in 2003 [13]. In 2008, the Dutch government eased the regulations on permits for hospitals to perform specific cardiac interventions in order to anticipate the future need for PCI, after which the number of offsite PCI centres further increased [14]. To keep their permits, off-site PCI centres are required to perform a minimum of 600 PCI procedures annually.

Currently, there are 30 PCI centres in the Netherlands, of which 14 are off-site PCI centres. However, it remains unknown to what extent the expansion of off-site PCI centres has impacted ambulance driving times for STEMI patients on a national scale. We evaluated the ambulance driving time to a centre for primary PCI care in the Netherlands. In addition, we investigated to what degree off-site PCI centres have contributed to a reduction in ambulance driving times.

\section{Methods}

\section{Study design}

We conducted a study assessing the accessibility of primary PCI care in the Netherlands, measured by ambulance driving time. We compared ambulance driving time in two settings: (1) a setting where PCI is only performed at on-site PCI centres, and (2) the current setting that includes on-site and off-site PCI centres.

\section{Data collection}

We obtained a dataset containing the number of inhabitants per four-digit postal code in the Netherlands in 2016 from Statistics Netherlands (CBS). We then used four-digit postal code polygon data describing the geographical coordinates of every Dutch postal code in the same year. We obtained a list of all on-site and off-site PCI centres from the Netherlands Society of Cardiology (NVVC) and the Dutch Association for
Thoracic Surgery (NVT). Of note, all PCI centres in the Netherlands perform primary PCI on a $24 / 7$ basis. We collected geographical coordinates of the listed hospitals by entering their addresses into an online coordinate converter (https://www.gps-coordinates. net) (NH). We visually checked the hospitals' coordinates using a satellite map (https://www.google.com/ maps).

\section{Data and statistical analyses}

For the analysis, we used a dataset containing all possible ambulance driving routes between geometric centres (centroids) of four-digit postal codes in the Netherlands in 2015. The calculations were based on a shortest-route algorithm. To estimate the ambulance driving time, we used historical data from the ambulance transportation records and the known speed limit for each road section. We then calculated the ambulance driving time from each four-digit postal code centroid to the centroid of the nearest PCI centre. We assumed that ambulances transporting STEMI patients operate with the highest priority (A1, for possible life-threatening situations). The ambulance driving time was estimated for both on-site and off-site PCI centres. The dataset was produced by an external party (CityGIS, The Hague, the Netherlands) on behalf of the National Institute for Public Health and the Environment (RIVM).

We displayed accessibility to PCI care by plotting the ambulance driving time to the nearest PCI centre from each four-digit postal code centroid on a map. In addition, we combined the ambulance driving time to the nearest PCI centre from each postal code with the number of inhabitants per postal code area. We then plotted the ambulance driving time and the corresponding fraction of the population nearest to an onsite or off-site PCI centre. We compared median driving distances and corresponding interquartile ranges (IQRs) using the Wilcoxon signed rank test. In addition, we used the paired $t$-test to compare means and standard deviations. We assessed the fraction of the population living $\leq 120 \mathrm{~min}$ from a PCI centre. Additionally, we assessed the fraction of the population living $\leq 60$ kilometre $(\mathrm{km})$ from any PCI centre. We used $60 \mathrm{~km}$ as a cut-off, because a previous Dutch study demonstrated that a distance of $>60 \mathrm{~km}$ from a PCI centre is associated with an increased total ischaemic time in STEMI patients [15]. All data and statistical analyses were performed using R (GJK and HG).

\section{Results}

On 1 January 2019, there were 30 PCI centres in the Netherlands: 16 on-site and 14 off-site centres (listed in the Appendix). We calculated 4046 centroids for the Dutch four-digit postal code areas. 
Table 1 Ambulance driving time to percutaneous coronary intervention centres in the Netherlands

\begin{tabular}{|c|c|c|c|}
\hline & Time to on-site $\mathrm{PCl}$ centre $(n=16)$ & Time to any $\mathrm{PCl}$ centre $(n=30)$ & $P$-value \\
\hline \multicolumn{4}{|l|}{ All PC4 areas } \\
\hline Median (IQR) & $18.8(12.2-26.3)$ & $14.9(8.9-20.9)$ & $<0.001$ \\
\hline Mean \pm SD & $21.5 \pm 21.0$ & $16.4 \pm 18.8$ & $<0.001$ \\
\hline \multicolumn{4}{|c|}{$P C 4$ areas affected by off-site $P C l$ centres } \\
\hline Median (IQR) & $25.4(18.2-33.1)$ & $14.7(8.9-20.9)$ & $<0.001$ \\
\hline Mean \pm SD & $27.8 \pm 15.0$ & $15.5 \pm 9.2$ & $<0.001$ \\
\hline \multicolumn{4}{|c|}{ Mainland PC4 areas } \\
\hline Median (IQR) & $18.7(12.1-26.2)$ & $14.8(8.8-20.8)$ & $<0.001$ \\
\hline Mean \pm SD & $20.3 \pm 12.5$ & $15.2 \pm 8.0$ & $<0.001$ \\
\hline \multicolumn{4}{|c|}{ Non-mainland PC4 areas } \\
\hline Median (IQR) & $288.6(111.6-306.2)$ & $288.6(87.4-306.2)$ & 0.008 \\
\hline Mean \pm SD & $212.4 \pm 98.4$ & $205.0 \pm 107.0$ & 0.005 \\
\hline
\end{tabular}

\section{Ambulance driving time}

The median ambulance driving time was $18.8 \mathrm{~min}$ (IQR 12.2-26.3) when only on-site PCI centres were included and $14.9 \mathrm{~min}(8.9-20.9)$ to any PCI centre $(p<0.001)$. In postal code areas with a reduction in ambulance driving time after the expansion of off-site PCI, the median ambulance driving time decreased from $25.4(18.2-33.1)$ to $14.7 \mathrm{~min}(8.9-20.9)(p<0.001)$. The reduction in estimated driving time after the establishment of a nearby off-site PCI centre ranged from 0.1-67.0 min. Differences in driving time to an on-site or any PCI centre for mainland and nonmainland areas (Wadden Islands) are displayed in Tab. 1 .

\section{$\mathrm{PCl}$ accessibility to the Dutch population}

Fig. 1 shows the estimated ambulance driving time from each Dutch postal code area to the nearest PCI centre. Patients on the mainland could be transferred to any on-site or off-site PCI centre in $\leq 120 \mathrm{~min}$. Fig. la shows the driving time to the nearest on-site PCI centre, while the ambulance driving time to any PCI centre (on-site or off-site) is displayed in Fig. $1 \mathrm{~b}$.

In $2016,17,080,825$ people were living in the Netherlands, who were served by 30 PCI centres; this amounts to approximately 569,000 individuals per PCI centre. Most of the population $(99.81 \%$; $n=17,049,945$ ) lived $\leq 60 \mathrm{~km}$ from a PCI centre. The fraction of the Dutch population with access to PCI care in the Netherlands based on ambulance driving time is displayed in Fig. 2. A total of $99.86 \%$ $(n=17,068,005)$ of the Dutch population could be transported to an on-site PCI centre $<90 \mathrm{~min}$. After the expansion of off-site PCI centres, $99.94 \%$ $(n=17,080,360)$ of the population could be transported to any PCI centre $<90 \mathrm{~min}$ (Tab. 2).
Fig. 1 Ambulance driving time to percutaneous coronary intervention $(P C l)$ centres in the Netherlands from any Dutch postal code area. a Time to nearest PCI centre with on-site surgical back-up for coronary artery bypass grafting (CABG). b Current situation in the Netherlands: time to any $\mathrm{PCl}$ centre, including offsite $\mathrm{PCl}$ centres

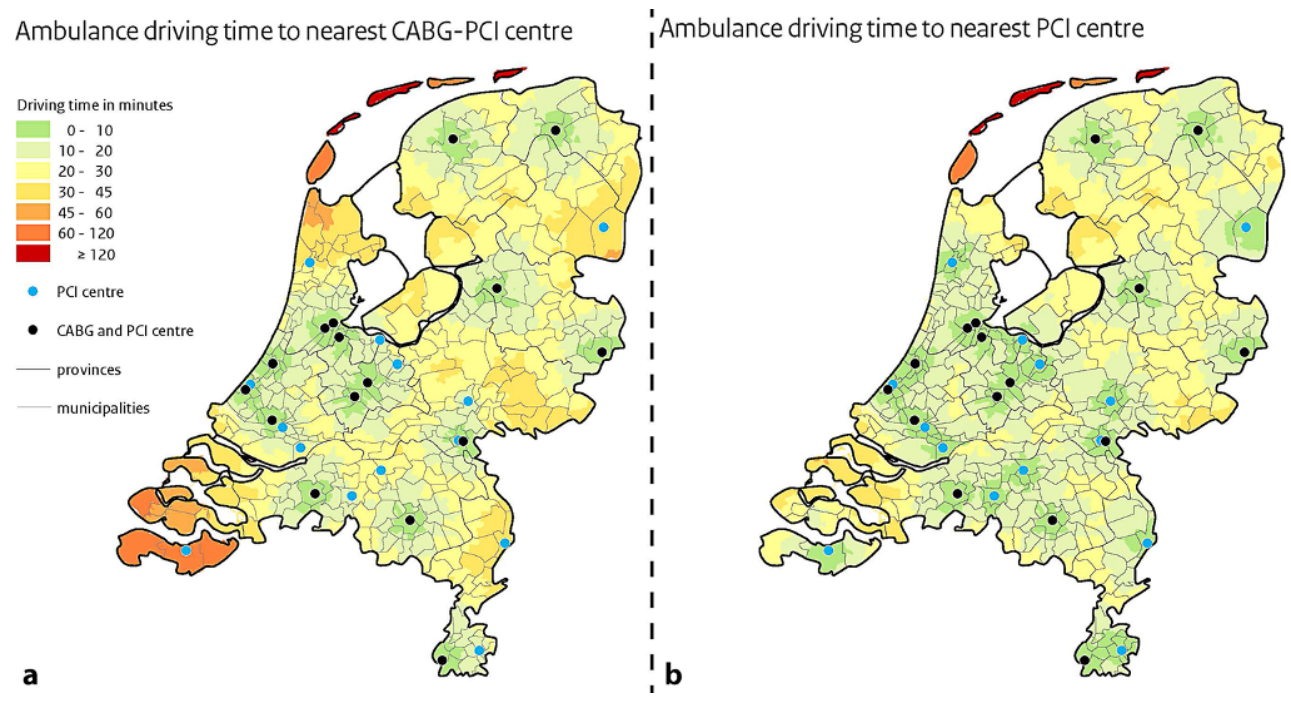


Fig. 2 Ambulance driving time to on-site or any percutaneous coronary intervention $(P C l)$ centre for cumulative proportion of Dutch population

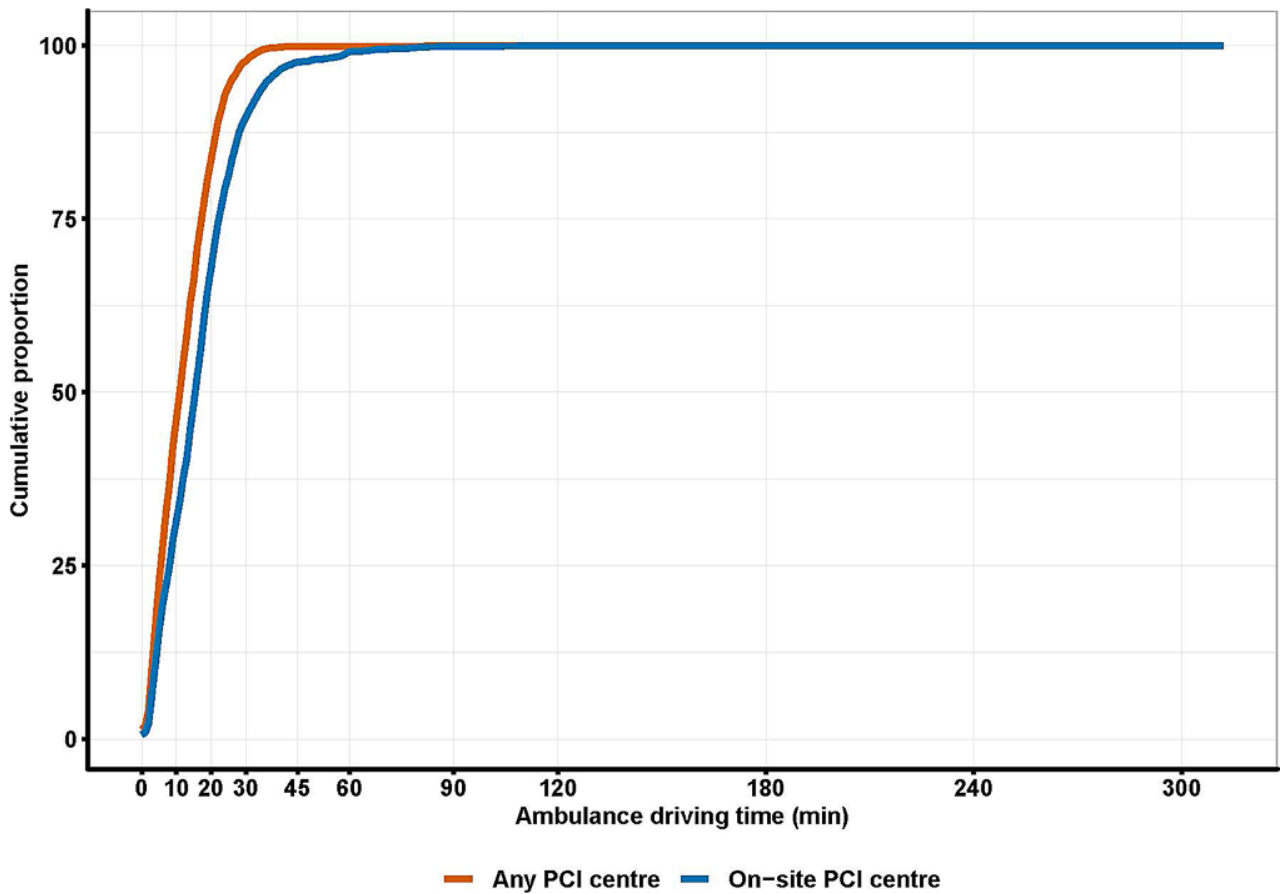

Table 2 Time frames for Dutch population to be transported to a percutaneous coronary intervention centre

\begin{tabular}{l|l|l|}
$\begin{array}{l}\text { Ambulance driving time } \\
\text { (minutes) }\end{array}$ & $\begin{array}{l}\text { On-site PCl centre } \\
(n=16)\end{array}$ & Any PCl centre $(n=30)$ \\
\hline$>120$ & $0.040 \%(6880)$ & $0.040 \%(6880)$ \\
\hline$\leq 120$ & $99.96 \%(17,085,170)$ & $99.96 \%(17,085,170)$ \\
\hline$<90$ & $99.86 \%(17,068,005)$ & $99.94 \%(17,080,360)$ \\
$<60$ & $98.89 \%(16,902,065)$ & $99.86 \%(17,068,005)$ \\
$<45$ & $97.47 \%(16,659,380)$ & $99.83 \%(17,063,080)$ \\
$<30$ & $88.67 \%(15,155,715)$ & $97.41 \%(16,648,730)$ \\
$<20$ & $64.78 \%(11,072,460)$ & $80.88 \%(13,823,585)$ \\
$<10$ & $28.83 \%(4,926,940)$ & $42.34 \%(7,236,095)$
\end{tabular}

$\mathrm{PCl}$ percutaneous coronary intervention

\section{Discussion}

This is the first study to report the impact of off-site PCI centres on accessibility to PCI care on a national scale. Our findings demonstrated that almost every individual in the Netherlands lives within $120 \mathrm{~min}$ from a primary PCI centre. In addition, we observed a significant reduction in the median driving distance to any PCI centre, which can be attributed to the expansion of off-site PCI centres.

\section{Context and interpretation}

Our results showed that the current distribution of PCI centres in the Netherlands ensures a high level of accessibility. We demonstrated that almost every individual in the Netherlands lives $\leq 120 \mathrm{~min}$ from a PCI centre (except for inhabitants of certain Wadden Islands). This indicates PCI-mediated reperfusion rather than a pharmacoinvasive strategy can be provided to all Dutch STEMI patients, in accordance with European Society of Cardiology guidelines [4]. Moreover, $99.9 \%$ of Dutch inhabitants could be transported to a PCI centre in $<60 \mathrm{~min}$ and $97.4 \%$ in $<30 \mathrm{~min}$, which can contribute to adherence to the European recommendations of a target STEMI diagnosis-towire crossing time of $\leq 90 \mathrm{~min}$.

A large Swedish study of $>10,000$ STEMI patients demonstrated that a first medical contact-to-PCI delay of $>1 \mathrm{~h}$ is associated with an increase in mortality (first medical contact-to-PCI 61-90 versus <30 min: hazard ratio 1.57 ; 95\% confidence interval 1.03-2.41) [16]. Therefore, the short transportation delays in the current study indicated that the current distribution of PCI centres contributes to the quality of care and outcome of ACS patients in the Netherlands.

We observed that $99 \%$ of the population lived $\leq 60 \mathrm{~km}$ from a PCI centre. This cut-off was based on a study of $>4000$ STEMI patients from a large onsite PCI centre in the Netherlands [15]. This study demonstrated an independent association between ischaemic time and driving distance $>60 \mathrm{~km}$ among STEMI patients who first present at a non-PCI 'spoke' centre. However, this finding was not observed in patients for whom the driving distance was $>60 \mathrm{~km}$ and who immediately called the ambulance services. Possibly, a transportation delay does not increase ischaemic time among ambulance patients in a small and densely populated country such as the Netherlands, because this delay is balanced by the additional preparation time of the catheterisation laboratory at the PCI centre, which contributes to a shorter doorto-balloon time. In Sweden, approximately $55 \%$ of the population live $<60 \mathrm{~km}$ from an on-site PCI centre and 
approximately $75 \%$ of the population are $<60 \mathrm{~km}$ from any 24/7 PCI centre [17]. However, due to several country-specific differences, including geographical differences, caution should be used when directly comparing the two countries and their healthcare systems. Moreover, despite longer driving distances to PCI centres, STEMI care in Sweden is regarded among the best in the world [18, 19].

The number of off-site PCI centres has increased, and these centres are regarded as safe when compared with on-site PCI centres [11, 12, 20, 21]. In the UK, emergency cardiac surgery after off-site PCI occurs in $<0.1 \%$ of patients [12]. Time delay in STEMI patients significantly decreased at two individual Dutch hospitals after they started offering off-site PCI $[13,22]$. These findings support off-site (primary) PCI. Conversely, Denmark has implemented a more centralised approach. Only four primary PCI centres serve approximately 5.5 million individuals $( \pm 1.4$ million inhabitants per centre), after two high-volume PCI centres merged into one very large centre performing 1000 primary PCIs annually [23]. After this merger, quality of care was maintained, and the symptom-to-balloon time was decreased by $30 \mathrm{~min}$ $(p<0.001)$. Moreover, a Danish nationwide study could not demonstrate an association between distance to a PCI centre and improved outcome in outof-hospital cardiac arrest patients, supporting the centralised strategy [24].

\section{Implications}

Ten years ago, the expansion of off-site primary PCI centres in the Netherlands sparked reactions, from both supporters and opponents [25, 26]. Our results showed off-site PCI centres improve accessibility to PCI care. It seems unlikely that additional expansion of off-site PCI will further benefit the accessibility. This year, the Dutch Healthcare Inspectorate (IGJ) reported that every off-site PCI centre is able to perform the minimum number of 600 PCIs per year [27]. However, some off-site PCI centres are unable to guarantee 24/7 primary PCI care. Moreover, off-site PCI centres were ordered to improve their collection of procedural and outcome data, which will be overseen by the recently established Netherlands Heart Registry.

\section{Strengths and limitations}

One of the strengths of this study is the use of reliable data from government institutions to display a simple structure indicator reflecting one aspect of the quality of a healthcare system [28].

However, there are some limitations. First, our study focused on the impact of off-site PCI expansion on time delays in STEMI patients. However, other local initiatives that were concomitantly introduced, such as prehospital ECG transmission or a home-tohospital feedback dashboard, have also led to shorter time delays $[29,30]$. Second, we used historical ambulance transportation records to build a model to estimate ambulance driving time. Therefore, this study does not fully reflect real-life clinical practice since we did not account for local practice agreements, for example rotating on-call PCI centres in the Rotterdam region. Third, we estimated ambulance driving times for non-mainland areas. However, since 2016, STEMI patients in these areas can be transported by a helicopter, which significantly reduces delays [31]. Fourth, we did not assess the impact of off-site PCI centres on individual patient outcomes. Fifth, we have only presented results from the Netherlands, a small country with a tight network of general hospitals and PCI centres and without any significant geographical barriers than can complicate logistics. Finally, we did not account for individuals residing close to the borders who may undergo PCI in Belgium or Germany.

\section{Conclusion}

Based on a computational model, the expansion of off-site PCI centres in the Netherlands has reduced the ambulance driving time to PCI centres in this country. It seems unlikely that additional expansion will further improve accessibility to PCI. Future efforts to improve PCI and ACS care should focus on strengthening the collaboration between general practitioners, ambulance services, and off-site and on-site PCI centres, and on further development of the Netherlands Heart Registry.

Conflict of interest N.P.G. Hoedemaker, R.J. de Winter, G.J. Kommer, H. Giesbers, R. Adams, S.E. van den Bosch and P. Damman declare that they have no competing interests.

Open Access This article is licensed under a Creative Commons Attribution 4.0 International License, which permits use, sharing, adaptation, distribution and reproduction in any medium or format, as long as you give appropriate credit to the original author(s) and the source, provide a link to the Creative Commons licence, and indicate if changes were made. The images or other third party material in this article are included in the article's Creative Commons licence, unless indicated otherwise in a credit line to the material. If material is not included in the article's Creative Commons licence and your intended use is not permitted by statutory regulation or exceeds the permitted use, you will need to obtain permission directly from the copyright holder. To view a copy of this licence, visit http://creativecommons.org/licenses/by/4.0/.

\section{Appendix}

\section{List of on-site PCl centres}

Amphia Ziekenhuis, location Molengracht (Breda); Amsterdam University Medical Center, location Amsterdam Medical Center and location VU University Medical Center (Amsterdam); Erasmus Medical Center (Rotterdam); Catharina Ziekenhuis (Eindhoven); 
HagaZiekenhuis, location Leyweg (Den Haag); Isala (Zwolle); Leiden University Medical Center (Leiden); Maastricht University Medical Center+ (Maastricht); Medical Centre Leeuwarden (Leeuwarden); Medisch Spectrum Twente (Enschede); Onze Lieve Vrouwe Gasthuis, location Oost (Amsterdam); Radboud University Medical Centre (Nijmegen); St. Antonius Ziekenhuis (Nieuwegein); University Medical Center Groningen (Groningen); University Medical Center Utrecht (Utrecht).

\section{List of off-site PCl centres}

Albert Schweitzer Ziekenhuis, location Dordwijk (Dordrecht); Canisius-Wilhelmina Ziekenhuis (Nijmegen); Elisabeth-TweeSteden (Tilburg); HMC Westeinde (Den Haag); Jeroen Bosch Ziekenhuis (Den Bosch); Maasstad Ziekenhuis (Rotterdam); Meander Medical Centre (Amersfoort); Noordwest Ziekenhuisgroep, location Alkmaar (Alkmaar); Rijnstate Ziekenhuis (Arnhem); Tergooi, location Blaricum (Blaricum); Treant Ziekenhuis, location Scheper (Emmen); VieCuri Medical Centre (Venlo); ZorgSaam Zeeuws-Vlaanderen (Terneuzen); Zuyderland Medical Centre, location Heerlen (Heerlen).

\section{References}

1. Neumann FJ, Sousa-Uva M, Ahlsson A, et al. 2018 ESC/ EACTS guidelines on myocardial revascularization. Eur Heart J. 2019;40:87-165.

2. Szummer K, Wallentin L, Lindhagen L, et al. Improved outcomes in patients with ST-elevation myocardial infarction during the last 20 years are related to implementation of evidence-based treatments: experiences from the SWEDEHEART registry 1995-2014. Eur HeartJ.2017;38:3056-65.

3. Terkelsen CJ, Sorensen JT, Maeng M, et al. System delay and mortality among patients with STEMI treated with primary percutaneous coronary intervention. JAMA. 2010;304:763-71.

4. Ibanez B, James S, Agewall S, et al. 2017 ESC Guidelines for the management of acute myocardial infarction in patients presenting with ST-segment elevation: The Task Force for the management of acute myocardial infarction in patients presenting with ST-segment elevation of the European Society of Cardiology (ESC). Eur Heart J. 2018;39:119-77.

5. Rasmussen MB, Frost L, Stengaard C, et al. Diagnostic performance and system delay using telemedicine for prehospital diagnosis in triaging and treatment of STEMI. Heart. 2014;100:711-5.

6. Knot J, Widimsky P, Wijns W, et al. How to set up an effective national primary angioplasty network: lessons learned from five European countries. EuroIntervention. 2009;5:299-309.

7. Bradley EH, Herrin J, Wang Y, et al. Strategies for reducing the door-to-balloon time in acute myocardial infarction. NEngl J Med. 2006;355:2308-20.

8. Yang EH, Gumina RJ, Lennon RJ, et al. Emergency coronary artery bypass surgery for percutaneous coronary interventions: changes in the incidence, clinical characteristics, and indications from 1979 to 2003 . J Am Coll Cardiol. 2005;46:2004-9.
9. Shah RU, Henry TD, Rutten-Ramos S, et al. Increasing percutaneous coronary interventions for ST-segment elevation myocardial infarction in the United States: progress and opportunity. JACC Cardiovasc Interv. 2015;8(1 Pt B):139-46.

10. Buckley JW, Bates ER, Nallamothu BK. Primary percutaneous coronary intervention expansion to hospitals without on-site cardiac surgery in Michigan: a geographic information systems analysis. Am HeartJ. 2008;155:668-72.

11. Goel K, Gupta T, Kolte D, et al. Outcomes and temporal trends of inpatient percutaneous coronary intervention at centers with and without on-site cardiac surgery in the United States. JAMA Cardiol. 2017;2:25-33.

12. Garg S, Anderson SG, Oldroyd K, et al. Outcomes of percutaneous coronary intervention performed at offsite versus onsite surgical centers in the united kingdom. J Am Coll Cardiol. 2015;66:363-72.

13. Peels HO, de Swart H, Ploeg TV, et al. Percutaneous coronary intervention with off-site cardiac surgery backup for acute myocardial infarction as a strategy to reduce doorto-balloon time. Am J Cardiol. 2007;100:1353-8.

14. Dutch government. Planningsbesluit bijzondere interventies aan het hart 2008. 2008. https://wetten.overheid.nl/ BWBR0023804/2008-05-07, updated 8 March 2019. Accessed June 192019.

15. Postma S, Dambrink JH, de Boer MJ, et al. The influence of residential distance on time to treatment in ST-elevation myocardial infarction patients. Neth HeartJ.2014;22:513-9.

16. KoulS, Andell P, Martinsson A, et al. Delay from first medical contact to primary PCI and all-cause mortality: a nationwide study of patients with ST-elevation myocardial infarction. JAm HeartAssoc. 2014;3:e486.

17. Lindholm D, James S, Lagerqvist B, Hlatky MA, Varenhorst C. New method for assessing the effect of driving distance to hospital care: using openstreetmap routing in cardiovascular research. Circ Cardiovasc Qual Outcomes. 2017;10:e003850. https://doi.org/10.1161/ CIRCOUTCOMES.117.003850.

18. Luscher TF, Obeid S. From Eisenhower's heart attack to modern management: a true success story! Eur Heart J. 2017;38:3066-9.

19. Chung SC, Sundstrom J, Gale CP, et al. Comparison of hospital variation in acute myocardial infarction care and outcome between Sweden and United Kingdom: population based cohort study using nationwide clinical registries. BMJ.2015;351:h3913.

20. Aversano T, Lemmon CC, Liu L, Atlantic CI. Outcomes of PCI at hospitals with or without on-site cardiac surgery. NEngl J Med. 2012;366:1792-802.

21. Jacobs AK, S-LT Normand, Massaro JM, et al. Nonemergency PCI at hospitals with or without on-site cardiac surgery. NEngl J Med. 2013;368:1498-508.

22. Koolen KH, Mol KA, Rahel BM, et al. Off-site primary percutaneous coronary intervention in a new centre is safe: comparing clinical outcomes with a hospital with surgical backup. Neth Heart J.2016;24:581-8.

23. Schoos MM, Pedersen F, Holmvang L, et al. Optimal catchment area and primary PCI centre volume revisited: a single-centre experience in transition from highvolume centre to "mega centre" for patients with ST-segment elevation myocardial infarction. EuroIntervention. 2015;11:503-10.

24. Tranberg T, Lippert FK, Christensen EF, et al. Distance to invasive heart centre, performance of acute coronary angiography, and angioplasty and associated outcome in out-of-hospital cardiac arrest: a nationwide study. Eur HeartJ.2017;38:1645-52. 
25. Zijlstra F, de Boer MJ. Should more hospitals in the Netherlands provide PCI without on-site cardiac surgery? Neth Heart J.2007;15:171-2.

26 . van der Graaf Y. Too many coronary intervention centres in the Netherlands. Ned Tijdschr Geneeskd. 2009;153:A947.

27. Health and Youth Care Inspectorate of the Netherlands (IGJ). Percutane Coronaire Interventie centra zonder hartchirurgie op locatie voldoen nog niet op alle terreinen aan de randvoorwaarden voor goede zorg. 2018. https://www.igj.nl/binaries/igj/documenten/ rapporten/2018/03/27/percutane-coronaire-interventiepci-centra-zonder-hartchirurgie-op-locatie-voldoennog-niet-op-alle-terreinen-aan-de-randvoorwaardenvoor-goede-zorg/Rapport+PCI+zonder+hartchirurgie. pdf, updated 8 March2018. Accessd June 192019.
28. Donabedian A. Evaluating the quality of medical care. MilbankMemFund Q. 1966;44(Suppl3):166-206.

29. Adams R, Appelman Y, Bronzwaer JG, et al. Implementation of a prehospital triage system for patients with chest pain and logistics for primary percutaneous coronary intervention in the region of Amsterdam, the Netherlands. Am J Cardiol. 2010;106:931-5.

30. Hermans MPJ, Velders MA, Smeekes M, et al. Call-to-balloon time dashboard in patients with ST-segment elevation myocardial infarction results in significant improvement in thelogistic chain. EuroIntervention. 2017;13:e564-e71.

31. RAV Fryslân (Regional Ambulance Services of Friesland province). Jaarverslag 2016. 2016. http:/ /www.rav-fryslan. $\mathrm{nl} /$ download/25, updated 19 June 2019. Accessed June 19 2019. 


\title{
Advertisement placed here.
}

\author{
ces bohn \\ CL van loghum
}

Houten 2020 


\title{
Advertisement placed here.
}

\author{
ces bohn \\ CL van loghum
}

Houten 2020 


\title{
Advertisement placed here.
}

\author{
ces bohn \\ CL van loghum
}

Houten 2020 


\title{
Advertisement placed here.
}

\author{
ces bohn \\ CL van loghum
}

Houten 2020 